\title{
O admirável mundo novo de Alexander Chayanov
}

\author{
RICARDO ABRAMOVAY
}

\section{O 1984 soviético}

$\mathrm{N}$

A NOITE DE 27 de outubro de 1921, depois de sair de uma assembléia na Escola Politécnica de Moscou e ouvindo ainda as intervenções enfáticas sobre a incompatibilidade entre o socialismo e o doce veneno da família burguesa, Alexis Kremniov estava em casa, com um livro de Herzen entre as mãos quando, sufocado por um odor estranho, pôde observar que os ponteiros do relógio de seu apartamento giravam cada vez mais rapidamente. Levantou-se e, sem reconhecer o rumo que tomava, caiu numa poltrona de onde só veio acordar no dia seguinte, ao som de uma voz feminina, percebendo que se encontrava num cômodo totalmente desconhecido. Pela janela viu que era Moscou, mas tudo parecia completamente mudado: faltavam prédios e em seus lugares estendiam-se imensos jardins, além de uma efervescência de automóveis e pessoas. Estremeceu diante da data do jornal: 5 de setembro de 1984. Kremniov tinha feito um salto de 63 anos.

Uma carta encontrada sobre a escrivaninha do quarto permitiu que ele compreendesse a razão pela qual era recebido por seus anfitriões com gentileza e solicitude. Era tomado por um norte-americano, Mr. Charlie Man, que vinha conhecer as realizações técnicas que tiveram lugar no país desde que ocorreu a grande revolução camponesa a qual, na década de 30 , pôs abaixo as imensas aglomerações urbanas e suprimiu a distância e a separação entre cidade e campo.

Obscurantismo generalizado? Retrocesso técnico? Ao contrário, o avanço revelado a Charlie Man por seus anfitriões russos (que não cessam de se espantar com seu sotaque moscovita tão perfeito e arcaico) é de tal ordem que até a meteorologia é controlada por meio de máquinas. Apesar disso, na agricultura predominam não a atividade mecânica, mas o labor cuidadoso dos jardins. Da mesma forma, a República camponesa (que conserva seu caráter soviético, um regime de sovietes camponeses) não é a volta ao isolamento e à autarcia, mas, ao contrário, um lugar de profundo e fértil convívio social em que o traço dominante é o contato cotidiano da população com toda forma de arte.

“Agora”, explica a Charlie Man um de seus anfitriões, "não há mais cidades, há somente o ponto de aplicação de um nó de conexões sociais. Cada uma de nossas cidades é simplesmente um lugar de encontro, a praça central do distrito. Não é um lugar em que se vive permanentemente, mas onde as pessoas desfrutam, reúnem-se e exercem várias atividades. É um ponto e não uma entidade social”. Em 
compensação os meios de comunicação são muito ágeis e em uma hora ou uma hora e meia, qualquer um pode estar nesses pontos de concentração.

A base social do país é a exploração camponesa individual, familiar, que o capitalismo vinha destruindo e à qual o socialismo imaginava ter dado a sentença de morte. "O senhor sabe, Mr. Charlie, que, durante o período socialista de nossa história, a exploração agrícola era tida como algo de inferior, uma espécie de protoplasma a partir do qual deveriam cristalizar-se as formas superiores da grande exploração coletiva, donde a velha idéia das fábricas de pão e de carne".

Mas ali, onde era necessária a cooperação entre vários trabalhadores, explica o anfitrião a seu suposto visitante norte-americano, os camponeses tinham organizado cooperativas, particularmente no que se refere à produção industrial na qual seria ingênuo contar com o renascimento da produção familiar. Essa distribuição populacional correspondeu também a um declínio importante do papel do Estado na vida do cidadão e a um reforço das entidades de poder local: "nosso sistema é, no fundo, construído de tal maneira que o senhor pode viver anos, suponhamos, no distrito de Volokolamsk, sem se lembrar uma só vez que existe um Estado enquanto poder coercitivo", lembra o anfitrião ao nosso herói.

O mundo encontrado por Alexis Kremniov entretanto, onde os camponeses não tinham aceitado se submeter ao domínio proletário e fizeram sua própria Revolução, estava dividido internacionalmente em cinco grandes blocos entre os quais a coexistência estava longe de ser pacífica. A República camponesa encontrava-se sob ameaça alemã e num passeio romântico pela feira de Belaia Kolp com a bela cunhada de seu anfitrião, a farsa em que se envolveu nosso herói é revelada quando a moça exclama, numa sala com autômatos de figuras históricas em ação (Lênin discursando no Congresso dos Sovietes, entre outros): olhe, é o seu retrato! E ele leu: Alexis Vassiliétithc Kremniov, membro do colégio do Conselho Mundial das economias nacionais, opressor do movimento camponês russo. Segundo parecer médico, atingido por mania de perseguição, degenerescência marcada pela assimetria do rosto e a conformação do crânio".

O capítulo 13 da novela é aquele no qual, como diz seu título, "Kremniov toma conhecimento da má organização dos lugares de reclusão neste país da utopia, assim como de algumas formas de seus procedimentos judiciários". Ele não tem outra saída senão contar para as autoridades locais sua estranha história. Não era um espião alemão, mas um homem que tinha vindo diretamente do passado. Entre os documentos e os episódios da época que ele é convidado a comentar diante de velhotes conhecedores de detalhes que escapavam aos manuais conhecidos, para verificar se sua história era real, ele teve de explicar o que era, por exemplo, a "urbanização da agricultura", evocação que o editor em francês do texto de Kremniov esclarece: era um projeto de 1918 que visava dar autonomia às cidades com relação ao abastecimento vindo do campo.

No último capítulo da novela (em que se lê: fim da primeira parte) a República repele o ataque aéreo alemão através das máquinas de controle meteorológico, a 
dívida de guerra é paga com dezenas de quadros renascentistas, mil gravuras chinesas da época Tang e mil touros reprodutores da famosa raça Nur für Deutschland.

E nós ficamos sem saber como nosso herói iria organizar a sua viagem de volta para o futuro que começava a ser construído com a Revolução de 1917.

\section{O cosmopolitismo da utopia camponesa}

Escrita por Alexander Chayanov, esta obra de neopopulismo futurista é assinada por um pseudônimo, Ivan Kremniov (1), cuja aventura, no romance, é relatada por seu irmão Alexis. É surpreendente que tenha sido publicada em 1920, com uma tiragem de 20 mil exemplares pela editora do Estado e, segundo Giovanni Mottura (1988:9), com autorização pessoal de Lênin. Recebe entretanto um prefácio de um alto diplomata bolchevique pelo quel se justifica a edição porque mostra não apenas a ideologia reacionária dos adeptos do cooperativismo, mas também que a "Rússia é um país camponês por excelência" e que no caminho para o socialismo o campesinato precisará de uma "regeneração interior".

A crítica do prefaciador - presidente das edições do Estado que defendia uma certa liberdade de imprensa até sofrer um atentado fatal em Lausanne, em 1923 dirigia-se àquilo que tornou o verdadeiro autor da novela célebre entre todos os estudiosos da relação entre agricultura e desenvolvimento: a unidade de produção camponesa.

Existe ambigüidade na maneira como o autor da novela trata o tema, e é exatamente aí que reside a riqueza de sua obra, e a razão pela qual é importante lembrar do nome de Chayanov/Kremniov quando se celebram os 80 anos da Revolução Russa.

Por um lado, ele se inscreve numa vasta galeria de utopistas russos cuja desconfiança com relação às cidades é imensa. O campo, nesse sentido, é o lugar da preservação das tradições, da família, das raízes nacionais, da força comunitária espontânea - em cujo poder transformador acredita a maioria dos revolucionários russos (mas não os bolcheviques, evidentemente) - daquilo que pode constituir a especificidade russa contra os ataques do pretenso universalismo ocidental. Convém lembrar, entretanto, que tal tradição anti-urbana parecia como que se materializar com a Revolução: Petrogrado passa de 2,3 milhões de habitantes em 1917 a 740 mil em 1920 e Moscou também perde parte importante de sua população.

Numa célebre entrevista concedida a H. Wells em 1920, e citada por Michel Niqueux, Lênin sustenta que as cidades no socialismo serão menores e completamente diferentes do que eram até então. Em suma, num país que às vésperas da Revolução tinha $82 \%$ de sua população vivendo no campo e mais de 17 milhões de estabelecimentos agrícolas (se é que esta noção pode ser aplicada às formas freqüentemente comunitárias de posse da terra existentes na Rússia), não é de se espantar, como o reconhece o prefaciador da novela de Chayanov/Kremniov, que surja a utopia camponesa. 
O outro lado da ambigüidade, entretanto, é fundamental: Alexander Chayanov, nascido em 1888, era economista, engenheiro agrônomo, conhecia profundamente a agricultura européia e mantinha contatos regulares com os mais destacados centros de produção científica em agronomia e ciências sociais. Um de seus mais célebres estudos foi publicado no periódico dirigido por Alfred Weber e Joseph Schumpeter na Alemanha. Ao final dos anos 20 ele publicou também na mais prestigiosa revista de economia agrícola dos Estados Unidos, o Journal of Farm Economics. Foi a junção da cultura européia com um profundo enraizamento local que permitiu a Chayanov elaborar a contribuição que, durante os anos 60, tornou-se referência internacional na economia do desenvolvimento. O estudo da unidade de produção camponesa exige a elaboração de categorias de pensamento que não fazem parte do repertório oferecido pelas ciências sociais: nem pela economia política marxista, nem pelos neoclássicos. A atribuição das categorias básicas de salário, capital, lucro e renda impede que se compreendam os comportamentos específicos e, aos olhos dos economistas, surpreendentes do campesinato.

A obra mais conhecida de Chayanov (1925/1986) começa relatando um episódio familiar a quem trabalha com a economia do desenvolvimento: a suposta resistência dos camponeses à adoção de inovações técnicas. Os agricultores da região de Perm recusavam-se a adotar uma inovação que, no entanto, lhes economizaria uma quantidade imensa de trabalho, a máquina de trilhar cereais. A razão dessa suposta aversão ao progresso estava no fato de que o trabalho deslocado pela máquina não poderia ser empregado produtivamente em qualquer outra atividade. Mais do que um teórico da economia camponesa, Chayanov elaborou uma teoria do funcionamento das unidades produtivas baseadas fundamentalmente no trabalho da família. Enquanto a renda dependesse fundamentalmente do trabalho familiar haveria um balanço entre a penosidade deste trabalho e as necessidades de consumo da família: uma vez preenchidas as necessidades, cada unidade adicional de trabalho passaria a ter, para a família, valor decrescente. Esta é a base teórica que permitia a Chayanov contestar a validade da lei da diferenciação social dos produtores, propondo em seu lugar uma espécie de diferenciação demográfica.

Existe atualmente uma vasta literatura comentando as teorias de Chayanov sobre o campesinato e já tratei o tema em outro trabalho (Abramovay, 1992). Todavia, nem sempre é colocado em destaque que ele não era o teórico do isolamento camponês. Ao contrário, o último capítulo de sua obra maior preconiza o cooperativismo e a integração vertical, citando explicitamente o exemplo da Dinamarca como forma mais eficiente de construção do socialismo na agricultura. Chayanov já antevia o desastre que ocorreria caso predominassem as teses que sustentavam a integração horizontal, ou seja, a formação de grandes unidades coletivas. Não que ele fosse contra as grandes fazendas coletivas, pois, durante o período em que, sob o regime soviético, ele ocupou responsabilidades na área de agricultura da Academia de Ciências (o que não deixa de ser surpreendente para alguém que tinha sido vice-ministro de Kerenski) chegou a calcular o tamanho ideal que poderiam ter algumas unidades com esse tipo de organização. O que Chayanov não queria que se 
perdesse era exatamente a grande organização social já existente na Rússia, tanto entre os próprios camponeses quanto entre os agrônomos.

Entre os camponeses, ele acreditava que tanto as formas tradicionais de cooperação (a obscina, a comuna rural, que regulava uma distribuição periódica da terra levando em conta o tamanho das famílias) quanto as implantadas com a modernização que se iniciou com a emancipação dos servos em 1861 (os zemstvos) podiam ser a base de um processo de cooperação no qual o trabalho familiar e, sobretudo, a iniciativa dos indivíduos fossem valorizados. O tema da obra de Chayanov, neste sentido, conserva toda a sua atualidade: de que maneira as sociedades contemporâneas podem compatibilizar o progresso técnico com o aproveitamento da energia e da iniciativa social que repousa nos indivíduos e nas famílias?

No capítulo nove da novela, em cujo título se lê "que as jovens leitoras podem pular, mas que é particularmente recomendado à atenção dos membros do Partido Comunista", o anfitrião de Mister Charlie, aliás, Alexis Kremniov, explica: "Se examinamos atentamente o mundo pré-socialista, veremos que sua máquina complexa era movida pelas forças da cupidez humana e pela fome. No sistema comunista, o trabalho continuava a existir como fato, é evidente, mas dele estava ausente todo esforço, pois não existia motivação. A ausência de estímulo fazia-se sentir não apenas sobre os executantes, mas também sobre os organizadores da produção, pois, como todo burocrata, eles viam seu interesse na perfeição do próprio funcionamento da economia, na precisão e no brilho do trabalho do aparelho econômico e não no resultado desse trabalho" (Kremniov, 1920/1976:60-61). Ora, para Chayanov, a Revolução não podia desperdiçar tal imensa energia produtiva e de organização representada pela massa da população camponesa, em nome de um futuro socialista cuja construção era inteiramente compatível com o desenvolvimento das unidades familiares de produção. Se para Lênin, a pequena propriedade mercantil era um viveiro de capitalismo, para Chayanov, ela era uma fonte permanente de riqueza para o país e nada era menos óbvio que sua tendência inelutável aos dois extremos da diferenciação social - a burguesia e o proletariado. Chayanov tinha razão quando falava da Dinamarca: o país tornou-se, a partir dos anos 1930, um verdadeiro paradigma em termos de modernização agrícola, mostrando o atraso representado pelo caminho que consistia na formação das fazendas (coletivas ou individuais) baseadas no assalariamento em larga escala.

Não era só entre os camponeses que essa organização tinha uma força impressionante, mas também entre os engenheiros agrônomos e os pesquisadores. Chayanov é o nome mais importante da chamada Escola da Organização da Produção e da Agronomia Social que produziu um volume de informações sobre o meio rural nunca posteriormente alcançado em qualquer país do mundo. Tal ligação entre um poderoso grupo de intelectuais com fortíssima raiz local fez da utopia camponesa de Chayanov não o anúncio obscurantista de uma volta ao passado, mas a base de um projeto cuja atualidade se mantém, não sob a forma apocalíptica por ele assumida no romance, mas por um tema hoje importantíssimo na agenda internacional, o dos laços rural-urbano. 
Se é verdade que a população rural no mundo todo está declinando, não é menos certo que aí se encontra um potencial econômico e organizativo para o qual o estudo da obra de Alexander Chayanov pode contribuir a valorizar. Os 80 anos da Revolução Russa devem servir não só para que o massacre humano cometido em nome dos ideais da superioridade da organização coletiva não seja esquecido, mas também para que se resgate aqueles que consagraram suas vidas à construção de um equilíbrio que, de fato, suprima as barreiras até hoje existentes entre cidade e campo.

Nota

1 Típico dos revolucionários da época, Kremniov evoca o sílex e, na sua forma adjetival, indica caráter firme, inquebrantável. É alusivo também aos muros de uma cidade (Kremlin), como explica Michel Niqueux (1976), editor minucioso da tradução francesa da obra.

Referências biliográficas

ABRAMOVAY, Ricardo. Paradigmas do capitalismo agrário em questão. São Paulo, Anpocs/Edunicamp/Hucitec, 1992, 275p. (Estudos Rurais, 12)

CHAYANOV, Alexander V. Peasant farm organization ( $\mathrm{l}^{\text {a }}$ ed. 1925) THORNER, Daniel, KERBLAY, Basile \& SMITH, R. E. F. (orgs.), com introdução de SHANIN, Teodor. Wisconsin, The University of Wisconsin Press, 1986.

KREMNIOV, Ivan. Voyage de mon frère Alexis au pays de l'utopie paysanne. $\left(1^{\text {a }} \mathrm{ed}\right.$. 1920) Paris, L’Âge de l'Homme, 1976.

MOTTURA, Giovanni. Prefazione. In: CAJANOV, Alexander Vavil'evic. L'Economia di lavoro. Milão, Scritti Scelti a cura di Fiorenzo Sperotto - Franco Angeli/Insor, 1988.

NIQUEUX, Michel. Postface - Dans laquelle le lecteur curieux trouvera quelques points de repère sur l'utopie de Kremniov, son temps et son véritable auteur. In: KREMNIOV (1920/1976), cit.

Ricardo Abramovay é professor do Departamento de Economia, Administração e Contabilidade da USP e do Programa de Pós-Graduação em Ciência Ambiental (Prolam) da USP.

O texto é versão ligeiramente modificada do que foi apresentado no seminário internacional A Revolução de outubro: 80 anos, organizado pelo Centro de Estudos sobre os Países Socialistas em Transformação e pelo IEA-USP, de 3 a 5 de novembro de 1997, em São Paulo. 